\title{
Empowering Youth Employment through European Digital Bootcamps (EDIBO)
}

\author{
Jorge E. Luzuriaga ${ }^{2}$, Begoña Sáiz Mauleón ${ }^{2,3}$, Olga Ampuero-Canellas ${ }^{4,5}$, Lenin G. \\ Lemus-Zúñiga ${ }^{1,2}$, Miguel A. Mateo Pla ${ }^{1,2}$, José V. Benlloch-Dualde ${ }^{1}$, Jimena González- \\ del-Río $^{4,5}$, Nereida Tarazona-Berenguer ${ }^{4,5}$ \\ ${ }^{1}$ Dpt. de Informática de Sistemas y Computadores, Universitat Politècnica de València \\ (UPV), Spain, ${ }^{2}$ Inst. Universitario de Tecnologías de la Información y Comunicaciones, \\ (UPV), Spain, ${ }^{3}$ Dpt. de Expresión Gráfica Arquitectónica, (UPV), Spain, ${ }^{4}$ Dpt. de Ingeniería \\ Gráfica, (UPV), Spain, ${ }^{5}$ Centro de Investigación en Tecnologías Gráficas, (UPV), Spain.
}

\begin{abstract}
Information and Communication Technologies (ICT) are transforming every area of economic and social life all around the world. New types of jobs different from the traditional ones are created rapidly. The demand for highly skilled staff who uses technology effectively has become a requirement for success of companies and the growing industry.

However, the number of IT graduates is not enough to meet the growing current demand. In addition, many small and medium-sized enterprises have little or no training programs to develop ICT skills. Initiatives from the European Economic Area and Norway Grants to support transnational projects for Youth Employment such as EDIBO, contribute to increase the job opportunities for young people who are neither in employment nor in education and training (NEETs). In this way, the Sustainable Development Goal 8 which aims to "promote sustained, inclusive and sustainable economic growth, full and productive employment and decent work for all" could be fulfilled.
\end{abstract}

Nowadays, EDIBO is developing different training programs in order to achieve a success model of all processes involved with the organization, implementation and evaluation. The aim of the work is to show the process that has resulted in the first bootcamp, recently launched in Spain as one of the cases implemented within the European framework.

Keywords: Bootcamp; ICT; youth employment; social project; entrepreneurship. 


\section{Introduction}

According to the World Health Organization, unemployment is the biggest epidemiological catastrophe for many societies and one of the main factors of social marginalization (Marmot, 2005). Young individuals (from 15 to 24 years) have a greater risk of ending up unemployed than older workers (Caliendo \& Schmidl, 2016) and their unemployment rates are generally much higher than total unemployment rates (European Union, 2018).

In 2017, Spain reported a $17.2 \%$ unemployment rate; the second highest of all the countries of the European Union (European Union, 2018). The number of young people between 16 and 29 years is 6,540,600 of which 1,092,100 are no longer in the education system and who are not working or being trained for work (NEET). The situation is higher in the range of age from 25 to 29 years, as figure 1 shows. (Informe Jóvenes y mercado de trabajo, 2018).

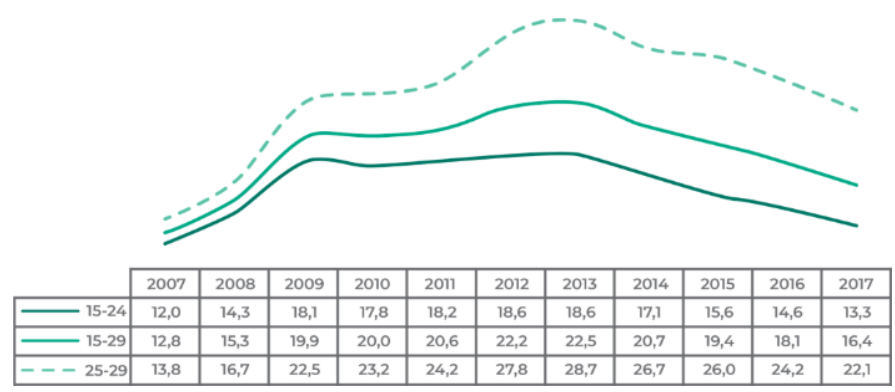

Figure 1. Unemployment in Spain by age in percentage. Source: Informe Jóvenes y mercado de trabajo, 2018.

In order to reduce these unemployment rates among young people, governments and institutions implement Active Labor Market Programs (ALMP) (Caliendo \& Schmidl, 2016). One of them, labour market training, includes any training intervention aimed at reinforcing their knowledges and skills. These programs are especially effective when there is an educational mismatch because courses and training permit to balance the unemployed skills with companies needs (Caliendo \& Schmidl, 2016).

Moreover, the International Telecommunications Union states that there will be tens of millions of jobs available for people who possess advanced digital knowledge and skills (Abbas \& Natta, 2018). Therefore, a training program in digital tools could increase the job opportunities of these unemployed young people, promoting their integration into the labor market.

To address this situation EDIBO project was launched, with the aim to enhance the employability of NEETS through formation in the area of ICT, with a special focus on people at risk of social exclusion. 
This European project is funded by Iceland, Liechtenstein and Norway through the EEA and Norway Grants and is being developed by seven partners: Three Thirds Society NPO (Greece) (Lead partner), Paralel-Silistra (Bulgaria), Foundation for Society (Latvia), Integration Centre (Lithuania), National Craftsmen Confederation Lecce (CNA Lecce) (Italy), FORMA.LAB SRL (Italy) and Universitat Politècnica de València (UPV) (Spain). The project lasts 36 months and began on 1st October 2018.

The remainder of this paper is structured as follows. Section 2 describes the methodology used in the project indicated by the Lead Partner. Section 3 presents the experimental part with the case study of the first EDIBO bootcamp in Valencia. Section 4 presents the results observed after 4 weeks of learning, and finally, section 5 with the conclusions describing both, the attitudes, behaviours and results of the knowledge acquired and the ongoing commitment by the collaborators enterprises.

\section{Methodology}

We proceed to comment the methodology established for the development of the bootcamps. This explanation is divided into five sections: network creation, syllabus, phases, target group and communication strategy.

\subsection{Network Creation}

Each EDIBO partner is responsible for designing, planning and running six bootcamps (two per year) based on the IT needs of the small and medium enterprises (SME) located in their regions. To do that each partner must create in its region a network composed of different stake holders: (i) SMEs, (ii) local and regional entities or associations, (iii) bootcamp participants and (iv) learning centre.

\subsection{Syllabus}

The project IT Expert Board must analyse the IT demands and needs of companies and then develop an intensive "digital training lab" adjusted to the needs detected. The model is inspired by the new "Rapid Technology Skills Training" of the World Bank, (Mulas 2019).

\subsection{Phases}

Training is carried out in two phases. First, students complete 200 hours of face-to-face classes and 200 hour internship in a company. The aim of the first phase is to enhance the technical knowledge in relation to some digital skills, and to strengthen English language and soft skills such as teamwork and entrepreneurship. Regarding the second phase, the objective is that students be involved in real projects within companies, in such a way they could increase their experience, self-esteem and elf-confidence to obtain a job. This is especially 
important in those students who do not have any previous work experience (Caliendo \& Schmidl, 2016).

\subsection{Target group}

The target group for the EDIBO training activities are unemployed young people aged from 18 to 29 who are neither studying nor working, with a special focus on the range 25-29 that comes from disadvantaged groups e.g. low-income, migrants, youngsters from rural areas. These are the characteristics that will guide the selection process of students.

Considering also that women are retreating from the fields of science and technology at alarming rates (Albert, 2016) creating a wide gender gap over the years (Castillo, 2014), EDIBO project plan to involve as many women as possible in the bootcamps, with the aim of having at least $35 \%$ female participants.

\subsection{Communication strategy}

The project has a communication plan whose primary goal is the widespread promotion and visibility of the project objectives and activities. It is also important to raise awareness and motivate young people and enterprises to participate in the bootcamps as students or sponsors.

The communication activities planned can be separated into three categories: conference organizations or info-days, mass communication media and publicity activities. Mainly social networks (Facebook, Twitter and YouTube), newspapers (digital editions) and radio will be used for the dissemination of messages.

\section{Experimental}

Next, we describe the development of the first bootcamp carried out in Valencia applying the methodology explained in the previous section. This first bootcamp, "Bootcamp 1: Full-Stack programmer with MEAN", started 3th of June and will run until 12th of August 2019. The number of students is about 25 , four of whom are women.

First, we contacted the following entities to create our first local network of collaborators:

- local SMEs: They helped us to define the profiles to obtain the IT needs to be able to pass the results to the IT Board to define the syllabus of the first bootcamp. In addition, some of them offered internship to bootcamp students.

- local and regional entities: Provincial Council, Official Association of Engineers, Chamber of Commerce and municipal transport company, among others. They joined to collaborate (a) in the diffusion of the project among their partners, (b) advertising the project to the 
society using the urban city buses, and (c) connecting with similar projects to exchange experiences.

- learning centre: a centre specialized in the development and implementation of training courses related with IT, was selected to share teaching activities.

The analysis of the IT local SMEs shows that Full Stack programmer is one the most demanded profile. Therefore, the content of the First Bootcamp was focused on the Full Stack developments. Table 1 shows the modules of this Bootcamp and their duration.

\begin{tabular}{|c|c|c|c|c|c|c|c|c|c|c|}
\hline 1 & 2 & 3 & 4 & 5 & 6 & 7 & 8 & 9 & 10 & 11 \\
\hline 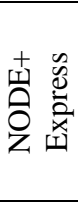 & $\begin{array}{l}\partial \\
\tilde{\hbar} \\
\Sigma\end{array}$ & $\begin{array}{l}0 \\
0 \\
Z \\
0 \\
\Sigma\end{array}$ & 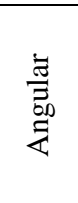 & 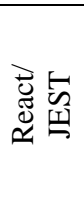 & 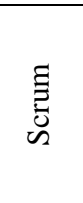 & 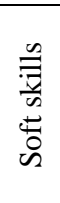 & 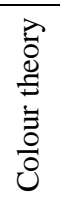 & 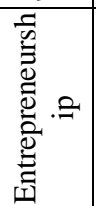 & 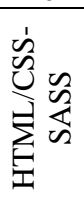 & 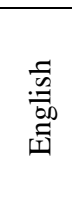 \\
\hline $24 \mathrm{~h}$ & $20 \mathrm{~h}$ & $24 \mathrm{~h}$ & $24 \mathrm{~h}$ & $24 \mathrm{~h}$ & $24 \mathrm{~h}$ & $4 \mathrm{~h}$ & $4 \mathrm{~h}$ & $4 \mathrm{~h}$ & $8 \mathrm{~h}$ & $40 \mathrm{~h}$ \\
\hline
\end{tabular}

EDIBO is much more than a labor market inclusion project. We believe that part of the project's success is based on emotional recover and self-confidence and that the approach of the project must to be based on human rights, seeking the integration of the values, principles and norms of the international human rights system into development plans, policies and processes (Fernández et al., 2010). Therefore, soft skills have been included in the courses.

Regarding teachers, most of them come from the academia, with a large teaching experience. However, there are some particular topics that need to be covered by people from companies. For example, the entrepreneurship module is taught by professionals who, in their professional life, are facing similar situations.

To select the 25 students, in addition to their personal data, two official documents were required: an identification card and the unemployment card. These documents will be used to validate the participants' age, home address and gender, and to observe the current status of unemployment and the time it takes in.

After analysing this information, people that not fit with the requirements were discarded and people that fit with were contacted by telephone/e-mail to make an interview. Then, the documentation was checked and a few questions regarding the motivation to participate in the bootcamp were raised.

Regarding the communication strategy used to promote the project, we considered that $86,4 \%$ of the Spanish population has access to the Internet, being the main type of broadband 
connection via a mobile phone (INE, 2019). So, two main processes have been defined: generic social networks campaigns and direct contact with associations representing potential students and firms (like Non-Government Organizations, local governments and the University Centre for Postgraduate Studies).

Also, two info-days were organized, in Valencia and Llíria, to raise awareness of EDIBO. Both obtained a good impact on the media, especially in local and regional digital newspapers.

\section{Results}

One of the best indicators of the success of the programme will be the number of trainees recruited at the end of their training period. Upon completion of the project, in 2021, the Spanish partner hopes to give IT formation at 150 unemployed youngsters and a tuition to promote entry into stable employment relationships.

As of July 2019, the first bootcamp has not yet finished, students are now in the face-to-face classes period, and it is only possible to report partial results. Therefore, it is too early to measure the impact of the bootcamp based on achieving social and educational objectives.

At present, five SMES have agreed to receive 20 students in internship programs, provided they finished the first training period. Human resources staff, from the learning centre, guides the internship of the students after an interview.

Different tests have been designed in each module to monitor the participants progress in their formation. For the moment all the students have passed these exams. This indicates that learning outcomes are been reaching. In addition, feedback from participants is received and registered by teachers in order to make a report.

After the first 25 sessions the teachers experience can be summarized as follows: i) understanding about web technology has improved; ii) students have learned to process the knowledge before applying it; iii) the more advanced students are helping the rest of the companions generating a good atmosphere in the course; iv) the level of self-esteem has increased; v) a transition from a skepticism feeling to a motivated inspiration has been detected; vi) in general the relationships between students are very good; vii) students have limited skills for self-learning; and viii) students required constantly attention from the teacher. 


\section{Conclusions}

Youth unemployment rates (NEETs) in Spain and Europe are a problem of concern to governments and institutions. On the other hand, digital development has created a large number of jobs. The union of these two realities gives rise to the EDIBO project, whose main objective is to improve youth unemployment by offering young people, especially those at risk of social or labour exclusion, a period of ICT training and work experience in companies.

Throughout, this document, all the stages developed by the Spanish partner for the execution of his first bootcamp are described with the aim to allow a rapid replication of the intensive ICT training in a social innovation community.

The preparation and implementation of this first bootcamp allowed us to draw the following preliminary conclusions.

Firstly, it is difficult to implement the same bootcamp in different geographical, social, economic and cultural areas like the ones involved in EDIBO. Therefore, it is important to apply the maximum to "plan globally but act locally". The lead partner operator has to contemplate the possibility of adapting the processed and activities to the idiosyncrasy of each region.

For instance, it was supposed that the content definition of bootcamp could be the same for all the partners, but then the experts agreed that the courses' contents should be adapted to the particularities of each partner.

Secondly, the possibility of adapting the program to the characteristics of each organization should also be considered. In the EDIBO project, five partners are NGOs but there is also a private institution and a public one whose structure and working mode differs in some points from the previous ones.

Thirdly, a project of this type can only get ahead with the close collaboration of SMEs and institutions (public or private). Companies collaboration is necessary firstly to define their IT needs and secondly to receive students during their internship period. The support of the institutions is important increase the project visibility as well as to reach companies and potential students in a quicker and easier way.

Concerning students, it has been observed that in certain cases the upgrading of their skills in IT technologies may not be enough to improve their employability. To overcome these difficulties, we have programmed three transversal skills modules out of a total of eleven purely technical content modules.

Finally, it is important to highlight that projects like this one contribute to the achievement of the Sustainable Development Goal 8. It is a way to strive that countries and their societies will be able to improve the lives of all, without leaving anyone behind. 


\section{References}

Abbas, A. B., \& Natta, W. (2018). How digital skills can help tackle youth unemployment. In International Trade Forum (No. 2, pp. 22-23). International Trade Centre.

Albert, C., \& Breternitz, R. (2016). Empowering Women's Success in Technology. Center for work \& familiy.

Archibald, R., Di Filippo, I., \& Di Filippo, D. (2012). The six-phase comprehensive project life cycle model including the project incubation/feasibility phase and the post-project evaluation phase. Pm World Journal, 1(2012), 1-33. https://doi.org/10.1016/j.jnoncrysol.2017.02.013

Caliendo, M., Schmidl, R. (2016). Youth unemployment and active labor market policies in Europe. IZA Journal of Labor Policy, 5(1), 1-30.

Castillo, R., Tacsir, E., \& Grazzi, M. (2014). Women in Science and Technology: What Does the Literature Say? | Publications. Inter-American Development Bank, (February), 32. Retrieved from https://publications.iadb.org/en/publication/11913/women-science-andtechnology-what-does-literature-say

European Union (2018) Key figures on Europe. STATISTICS ILLUSTRATED. 2018 edition. Luxembourg: Publications Office of the European Union, 2018. ISBN 978-9279-77871-1 ISSN 2315-201X doi: 10.2785/594777

Informe Jóvenes y mercado de trabajo. Subsecretaría de Trabajo, Migraciones y Seguridad Social. Dirección General de Estadística y Análisis Sociolaboral. Junio 2018. Ministerio de Trabajo, Migraciones y Seguridad Social. Gobierno de España. Retrieved July 1, 2019, frommhttp://www.mitramiss.gob.es/es/sec_trabajo/analisis-mercado-trabajo/jóvenes /numeros/2018/junio_2018.pdf

Fernández Juan, A., Borja Segade, C., García Varela, P., Hidalgo Lorite, R. (2010). Guía para la incorporación del enfoque basado en derechos humanos en las intervenciones de cooperación para el desarrollo. Instituto Universitario de Desarrollo y Cooperación de la Universidad Complutense de Madrid. NIPO: 502-13-045-4

Ignacio, G.-P., \& Pilar, C. G. M. (2013). The use of social technologies in Spanish young people: a global behaviour model in teenagers. Global Business Perspectives, 1(4), 289308. https://doi.org/10.1007/s40196-012-0006-z

INE, (2019). España en Cifras 2019. Instituto Nacional de Estadistica. NIPO:10419-002-2

Marmot, M. (2005). Social determinants of health inequalities. The lancet, 365(9464), 10991104.

Mulas, V., Paradi-Guilford,C. M., Allende Letona, E., \& Dalphond, Z. V. (2017). Coding bootcamps: building future-proof skills through rapid skills training (English). Washington, D.C.: World Bank Group. Retrieved July 1, 2019, from http://documents.worldbank.org/curated/en/795011502799283894/Coding-bootcampsbuilding-future-proof-skills-through-rapid-skills-training

"Social Determinants of Health. The Solid Facts" (OMS, 2003). http://www.euro.who.int/_data/assets/pdf_file/0005/98438/e81384.pdf 